\title{
SYNERGISTIC ANTIOXIDANT ACTION OF MURRAYA KOENIGII AND PLUMERIA RUBRA EXTRACTS ENHANCE HEPATOPROTECTIVE EFFICACY AGAINST METHOTREXATE INDUCED LIVER INJURY
}

\author{
ENGINEER A. S., PAL S., DESAI K. R., HIGHLAND H. N.,* \\ Department of Zoology, Biomedical Technology and, Human Genetics, Gujarat University, Ahmedabad 380009, Gujarat, India \\ Email: hnhighland@gujaratuniversity.ac.in
}

Received: 28 Jun 2017 Revised and Accepted: 31 Aug 2017

\begin{abstract}
Objective: The present study was focussed on evaluating the hepatoprotective capacity of a combination of leaf extracts of Murraya koenigii and Plumeria rubra on drug-induced toxicity in mice liver.

Methods: Hydromethanolic and aqueous extracts were prepared from the leaves of Murraya koenigii and Plumeria rubra. A combination of these extracts was tested as a dual formulation (DF). The extracts were evaluated for their antioxidant activity and phytochemical content. Healthy adult male mice were treated in five groups, for $30 \mathrm{~d}$ : Control (Group I-Untreated), Group II (Methotrexate at $10 \mathrm{mg} / \mathrm{kg}$ Body weight, intraperitoneally), Group III (Methotrexate+Silymarin), Group IV (Methotrexate+hydromethanolic extract of DF-250 mg/kg b.w., orally), Group V (Methotrexate+aqueous extract of the DF-250 mg/kg b.w. orally). After treatment, the animals were necropsied. Blood was collected for serum parameters such as alanine transaminase (ALT), Aspartate transaminase (AST) and $\gamma$ glutamyl transpeptidase (GGT). Further liver function tests like Alkaline phosphatase (ALP), Phosphorylase as well as Oxidative stress parameters like Lipid peroxidation (LPO), Superoxide dismutase (SOD), Catalase (CAT), along with the liver protein and cholesterol content were analyzed.

Results: Administration of both the DF extracts significantly ameliorated the methotrexate-induced toxic effects on all the aforementioned biochemical parameters. The hydromethanolic extract showed significant recovery in the liver function tests like ALT $(p<0.05)$ and AST ( $<<0.001)$. Antioxidant stress enzymes like SOD $(p<0.001)$ and Catalase $(p<0.001)$ also showed significant recovery after administration of both the extracts. The other parameters assayed also followed the same trend. Although both the extracts showed remarkable hepatoprotection, the hydromethanolic extract was found to be significantly more potent than the aqueous extract.
\end{abstract}

Conclusion: The present study concludes that the Dual formulation of the extracts of Murraya koenigii and Plumeria rubra could be an effective hepatoprotective agent due to the synergistic action of the phytoconstituents of both the plants.

Keywords: Mice, Liver, Dual formulation, Hepatoprotection

(C) 2017 The Authors. Published by Innovare Academic Sciences Pvt Ltd. This is an open-access article under the CC BY license (http://creativecommons.org/licenses/by/4.0/) DOI: http://dx.doi.org/10.22159/ijpps.2017v9i10.21004

\section{INTRODUCTION}

Since the liver is the principle site of metabolism, synthesis and processing (biotransformation) it is also the main target for xenobiotics, toxins and foreign substances entering the human body. Profuse supply of blood and the presence of many redox systems enable the liver to convert these substances into different kinds of inactive and active metabolites [1]. A large variety of compounds have been identified as hepatotoxins. Several therapeutic drugs have also been identified to cause hepatotoxicity. Due to the significant patient morbidity and mortality associated with Drug toxicity [2], several drugs have been withdrawn from the market. Although the exact mechanism of drug-induced liver toxicity (DILI) remains largely unknown, it appears to involve direct cell stress, mitochondrial impairment and adverse immune reactions [3].

The use of natural remedies for the treatment of liver diseases has a long history and medicinal plants and their derivatives are still used traditionally all over the world for this purpose. Scientific evaluation of plants has often shown that active principles or phytochemicals in these are responsible for therapeutic success. Although the development of hepatoprotective agents from potent plant resources is not new, the identification of an efficient, simple, cost-effective formulation with minimal adverse consequences is still much needed. Availability of pure components such as silymarin and its derivatives are scarce since the milk thistle is a rare species in India which increases the cost. Polyherbal formulations (PHFs) which have also been marketed are not without setbacks. They comprise of innumerable phytochemicals, which are potent antioxidants but are known to modulate the activities of various enzyme systems due to their interaction with various biomolecules [4]. In addition, Polyherbal treatments can interact with medications. The use of large quanta of herbal phytochemicals makes it difficult to adjust the proper dose of an individual component. Efferth and Koch [5] have described the complex interactions between phytochemicals present in such formulations. PHFs are beneficial to mankind in many aspects; but they are still challenged by some unavoidable drawbacks, affecting their ability and efficacy in treatments. Thus a viable alternative is the identification of dual herbal resource for a simpler, cost-effective, easily available hepatoprotective agent.

Therefore, based on earlier studies at our laboratory $[6,7]$ two plants Murraya koenigii and Plumeria rubra were selected and tested at an optimum dosage in a dual formulation for a more effective hepatoprotective agent. Murraya koenigii is a native of India Sri Lanka and other south Asian countries. It is found almost everywhere in the Indian subcontinent, excluding the higher levels of the Himalayas [8] and since it is extensively available, it has been a plant of choice for this study. Curry leaves are grown throughout India and used for its subtle flavouring. It is traditionally used as a whole or in parts as antiemetics, antidiarrheal, febrifuge, blood purifier, antifungal, depressant, anti-inflammatory, body aches, for kidney pain and vomiting [9]. Murraya koenigii is also used to combat heavy metal-induced toxicity [10]. The other plant selected for the dual formulation is Plumeria rubra. Plumeria rubra is a small tree 3.5-6.0 m in height and it is commonly grown in gardens for their ornamental purpose. In the traditional system of medicine of India Plumeria species are widely used as purgative, remedy for diarrhea, cure of itch, bronchitis, cough, asthma, fever, piles, dysentery, blood disorder and tumors. 
The present investigation was therefore designed to develop a dual herbal formulation taking advantage of proven hepatoprotective plant extracts in our lab, which could supplement each other in phytochemical components. The formulation was evaluated for its hepatoprotective efficacy against a drug-induced, an acute hepatotoxic model using adult mice.

\section{MATERIALS AND METHODS}

The present study was aimed at evaluating the hepatoprotective potential of a dual formulation containing a combination of leaf extracts of Murraya koenigii and Plumeria rubra against druginduced toxicity in Swiss male albino mice. Male albino mice weighing 35-40 g were treated with the Dual Formulation (DF) for $30 \mathrm{~d}$ against the drug-induced hepatotoxic model.

Healthy, adult, pathogen-free, male albino mice of Swiss strain (Mus musculus) were obtained from Cadilla Pharmaceuticals, Gujarat, India. Experiments were conducted as per the guidelines are given by the Commission for Purpose of Control and Supervision of Experiments on Animals (CPCSEA), India under registration no.167/1999/CPCSEA. The experimental protocol and number of animals used for the experiments were in accordance to acceptance regulations by the Institutional Animal Ethics Committee (IAEC).

\section{Chemicals}

Methotrexate was purchased from BDH Industries ltd., Mumbai. Silymarin used in the study was obtained from MP biomedicals, LLC, France. The diagnostic kits used for estimation of ALT and AST were purchased from Autospan Liquid Gold and Reckon Diagnostics Pvt. Ltd respectively. Moreover, all the other chemicals used for the present study were purchased from Hi-Media, India.

\section{Collection of plant material}

Fresh leaves of Plumeria rubra and Murraya koengii were collected from the Department of Zoology, Gujarat University. Authentication of the plant material (Murraya koengii and Plumeria rubra) used in the study was obtained from Dr. H. Solanki, Professor and Principal Taxonomist, Department of Botany, Gujarat University, Ahmedabad $\left(23.0225^{\circ} \mathrm{N}, 72.5714^{\circ} \mathrm{E}\right)$ with voucher numbers GU/BOT/R/M23 and GU/BOT/A/P19 respectively.

\section{Preparation of extract}

Preparation of the plant extracts was carried by soxhletion according to the method outlined by Harborne [11]. The collected leaves were washed thoroughly with distilled water and shade dried at room temperature. The dried leaves were then pulverized into a fine powder which was then subjected to defattation with petroleum ether. The defattation was carried out by stirring fine powder along with petroleum ether overnight on a magnetic stirrer. Extraction of the defatted powder was carried out through soxhlet apparatus. Two extracts were prepared: Hydromethanolic extract (70:30) and Aqueous extract. Qualitative analysis of the test extracts was carried out and the extracts were also tested for its antioxidant capacity before evaluating their hepatoprotective potential.

\section{Qualitative phytochemical screening tests}

The aqueous and hydromethanolic extract of the powdered plant material was subjected to various qualitative tests for the identification of various plant's phytochemical constituents present in the species [12].

\section{Antioxidant activity}

[DPPH (1, 1-diphenyl-2-picrylhydrazyl)]

The antioxidant activity of the extracts was evaluated by DPPH antioxidant assay, which was originally described by Blois [13].

\section{Principle}

DPPH (1, 1-diphenyl-2-picrylhydrazyl) is considered to be a stable radical because of paramagnetism conferred by its odd electron (delocalization of spare electron over the molecule as a whole). The solution (in methanol) appears as deep violet and shows strong absorbance at $520 \mathrm{~nm}$. DPPH radical can accept an electron or hydrogen radical to become a stable diamagnetic molecule and has pale violet color. If substance for testing antioxidant activity is mixed with DPPH solution and gives rise to pale violet color, it suggests that this substance has antioxidant effect by the mechanism of free radical scavenging activity $[13,14]$.

\section{Animal groups}

Study on male albino mice of 35-40 g was carried on, treatment was done for $30 \mathrm{~d}$. The animals were divided into different groups as mentioned below:

\section{Group 1: Control}

Control group animals were provided with standard food and distilled water.

\section{Group 2: Methotrexate}

Animals were injected with the dose methotrexate $(10 \mathrm{mg} / \mathrm{kg}$ body weight) intraperitoneally using a 26 gauge needle to induce toxicity in the target tissue at an interval of every $48 \mathrm{~h}$.

\section{Group 3: Methotrexate+Silymarin}

Animals were injected with methotrexate (intraperitoneally) along with silymarin $(100 \mathrm{mg} / \mathrm{kg}$ body weight $)$ which was given orally with the help of an oral gavage.

Group 4: Methotrexate+Hydromethanolic extract of dual formulation (DF)

Animals were administered methotrexate (intraperitoneally) along with oral hydromethanolic extract $(250 \mathrm{mg} / \mathrm{kg}$ body weight).

Group 5: Methotrexate+Aqueous extract of dual formulation

Animals were administered methotrexate (intraperitoneally) along with oral hydromethanolic extract $(250 \mathrm{mg} / \mathrm{kg}$ body weight).

On completion of the treatment duration, the animals were weighed on a digital balance (Repetach) and were necropsied according to OECD guidelines and CPCSEA specification. Organ of interest was taken out, blotted free of blood, washed with normal saline for further analysis. Blood was also collected for different serum parameters.

\section{Biochemical parameters}

\section{Alanine transaminase (ALT) (EC.2.6.1.2)}

ALT was estimated from the serum by Modified UV (IFCC) method using Autospan Liquid Gold kit reagents in IFCC kit and results obtained on automated Biochemical Analyser, were expressed as IU/l.

\section{Aspartate transaminases (AST) (EC.2.6.1.1)}

AST was estimated from the serum by IFCC method (using Reckon Diagnostics Pvt. Ltd. IFCC kit and the results obtained on automated Biochemical Analyser were expressed as IU/l.

\section{$\gamma$ Glutamyl transpeptidase (EC 2.3.2.2)}

$\gamma$ Glutamyl transpeptidase was from the serum by IFCC method (using Reckon Diagnostics Pvt. Ltd. IFCC kit and the results obtained on automated Biochemical Analyser expressed in units of IU/l.

\section{Phosphorylase (E. C. 2.4.1.1)}

Phosphorylase activity in liver of control and all treated groups of animals was assayed by the method of Cori et al. [15]. The final value was expressed as $\mu \mathrm{g}$ of inorganic phosphate released/mg protein/15'.

\section{Alkaline phosphatase (ALKpase) (E. C.3.6.1.3)}

Alkaline phosphatase activity was estimated in liver by the method of Bessy et al. [16]. Alkaline phosphatase in the sample catalyzes the hydrolysis of colorless p-nitrophenyl phosphate (p-NPP) to give pnitrophenol and inorganic phosphate. At the $\mathrm{pH}$ of the assay (alkaline), the p-nitrophenol is in the yellow phenoxide form. The rate of absorbance increase at $410 \mathrm{~nm}$ is directly proportional to the alkaline phosphatase activity in the sample. Optimized concentrations of zinc and magnesium ions are present to activate the alkaline phosphatase in the sample and the final activity was given as $\mu$ g of inorganic p-nitrophenol released/mg protein/15'. 


\section{Lipid peroxidation (LPO)}

The extent of membrane LPO was estimated by measuring the formation of malondialdehyde (MDA) using the method of Ohkawa et al. [17]. MDA is one of the end products of membrane LPO. Malonaldehyde (MDA) is the main end-product of polyunsaturated fatty acid peroxidation (PUFA) following reactive oxygen species (ROS) insult. The production of this aldehyde is used as a biomarker to measure the level of oxidative stress in an organism. The final value was stated as nM of MDA/mg tissue weight $/ 60 \mathrm{~min}$

\section{Superoxide dismutase EC (1.15.1.1)}

SOD was estimated as per the method suggested by Kakkar et al. [18]. In this method, the formazan formed at the end of the reaction indicates the presence of the enzyme. One unit of the enzyme activity is defined as the enzyme concentration required to inhibit $50 \%$ of the optical density of the chromogen formed in one minute at $560 \mathrm{~nm}$ under the assay condition expressed as units/mg protein

\section{Catalase (E. C.1.11.1.6)}

The catalase activity in liver, kidney and testis of control and al treated animals was assayed by the modified method of Sinha [19]. Potassium dichromate prepared in the acetic acid is reduced to chromic acetate when heated in the presence of $\mathrm{H}_{2} \mathrm{O}_{2}$ with the formation of perchromic acid as an unsuitable intermediate. The chromic acetate thus produced is measured calorimetrically at 570 $\mathrm{nm}$. The catalase preparation is allowed to split $\mathrm{H}_{2} \mathrm{O}_{2}$ for different periods of time. The reaction is stopped at a particular time by the addition of dichromate/acetic acid mixture and the remaining hydrogen is determined by measuring chromic acetate spectrophotometrically after heating the reaction. The final activity was given as $\mu$ moles $\mathrm{H}_{2} \mathrm{O}_{2}$ consumed $/ \mathrm{min} / \mathrm{mg}$ protein.

\section{Protein}

Protein levels in the liver of control and all treated groups of animals were estimated by the method of Lowry et al. [20]. The sample containing protein was treated with phenol reagent of FolinCiocalteau, a deep blue colour developed, due to two reactions occurring simultaneously, i.e. the reaction of alkaline copper sulphate solution with peptide bonds and the reduction of phosphomolybdic and phosphotungstic acids by aromatic amino acids present in the protein. The blue colour developed is quantitatively proportional to the total protein, which is measured on LABINDIA UV/VIS $3000+$ Spectrophotometer at $540 \mathrm{~nm}$ and expressed as $\mathrm{mg} / \mathrm{dL}$.

\section{Cholesterol}

The levels of the cholesterol in the liver of control and all treated groups of control and all treated groups of mice were estimated by the method of Zlatkis et al. [21]. In the presence of concentrated sulphuric acid and glacial acetic acid, cholesterol forms a coloured complex with ferric chloride $\left(\mathrm{FeCl}_{3}\right)$ which was measured on LABINDIA UV/VIS 3000+Spectrophotometer against blank. The final value was expressed as $\mathrm{mg} / \mathrm{dL}$.

\section{Statistical analysis of the data}

For each biochemical parameter, a minimum of 4- 5 replicates were done. Values are expressed as mean \pm S. E. The one way ANOVA was used to verify levels of significance at the $p<0.05$ value, using Graphpad Prism Version 6.

\section{RESULTS}

The results of the phytochemical screening, as well as the serum and biochemical analysis, revealed the following observations:

\section{Phytochemical screening}

The phytochemical test on hydro methanolic and aqueous plant extract of the dual formulation revealed the presence of various phytochemical constituents like alkaloids, glycosides, tannins, saponins, flavonoids, carbohydrates, steroids, triterpenoids and phenolic compounds. (table 1)

Table 1: Preliminary phytochemical screening of both hydro-methanolic and aqueous leaf extract of Murraya koenigii, Plumeria rubra and their dual extracts

\begin{tabular}{|c|c|c|c|c|c|c|c|}
\hline S. No. & Compound & M. koenigii HM & P. rubra HM & DF HM & M. koenigii AQ & P. rubra AQ & DF AQ \\
\hline 1. & Alkaloids & ++ & ++ & +++ & ++ & ++ & +++ \\
\hline 2. & Glycosides & ++ & ++ & +++ & - & ++ & ++ \\
\hline 3. & Tannins & ++ & ++ & ++ & ++ & ++ & ++ \\
\hline 4. & Saponins & + & - & + & + & - & + \\
\hline 5. & Flavonoids & +++ & +++ & +++ & +++ & +++ & +++ \\
\hline 6. & Carbohydrates & ++ & ++ & ++ & ++ & ++ & ++ \\
\hline 7. & Steroids & ++ & ++ & ++ & ++ & - & ++ \\
\hline 8. & Triterpenoids & + & + & + & + & - & + \\
\hline 9. & Phenolic compound & ++ & ++ & ++ & ++ & ++ & ++ \\
\hline
\end{tabular}

$\mathrm{HM}=$ Hydromethanolic extract, $\mathrm{AQ}=$ Aqueous, $\mathrm{DF}=$ Dual Formulation made by combining extracts of both plants, $(+)=$ presence and $(-)=$ absence, $\mathrm{n}=3$

\section{Antioxidant (DPPH) activity}

Free radical scavenging activity of leaf extracts of Murraya koenigii and Plumeria rubra in the form of dual hydromethanolic and aqueous extracts was quantitatively determined using DPPH assay. The results of the screening for both the extracts are given in table 2. The free radical scavenging ability of the dual extract was evaluated recording the change in absorbance produced by the reduction of
DPPH. The antioxidant capacity was expressed as $\mathrm{EC}_{50}$ which is the concentration of an antioxidant needed to trap $50 \%$ of DPPH absorbance. The results obtained were compared to ascorbic acid. Higher \% inhibition indicates better scavenging activity or antioxidant potential. Accordingly, a low $\mathrm{EC}_{50}$ value indicates a high antioxidant capacity. The $\mathrm{EC}_{50}$ values for antioxidant activity obtained for Ascorbic acid, Dual hydromethanolic and Dual aqueous extracts are $3.34,25$ and $28.32 \mu \mathrm{g} / \mathrm{ml}$ respectively.

Table 2: Percent antioxidant (DPPH) activity of ascorbic acid, dual hydro-methanolic and dual aqueous extracts

\begin{tabular}{llll}
\hline Concentration $(\boldsymbol{\mu g} / \mathbf{m l})$ & Ascorbic acid (Standard) & DF hydro-methanolic extract & DF aqueous extract \\
\hline 500 & $94.3 \pm 1.08$ & $83.79 \pm 2.3$ & $74.58 \pm 3.2$ \\
250 & $89.25 \pm 1.21$ & $82.37 \pm 0.8$ & $71.71 \pm 5.7$ \\
125 & $87.81 \pm 1.05$ & $80.50 \pm 2.0$ & $71.52 \pm 1.5$ \\
62.5 & $80.01 \pm 0.57$ & $83.79 \pm 1.4$ & $66.23 \pm 1.4$ \\
31.25 & $75.81 \pm 0.98$ & $57.65 \pm 4.9$ & $55.17 \pm 2.6$ \\
15.63 & $73.47 \pm 1.91$ & $34.79 \pm 1.8$ & $32.4 \pm 2.9$ \\
7.81 & $69.28 \pm 2.01$ & $21.15 \pm 2.4$ & $25.04 \pm 2.8$ \\
3.9 & $58.31 \pm 0.78$ & $3.47 \pm 3.5$ & $8.32 \pm 1.2$ \\
\hline
\end{tabular}

Values are mean $\pm S E M, n=3, D F=$ dual formulation 
Methotrexate-induced hepatotoxicity and its possible amelioration by dual extracts: Body weight

Body weights of control, methotrexate-treated and extract treated animals were monitored before and after drug administration.

As shown in fig. 1, there was no significant alteration in the body weights before and after the entire experiment in the control animals (Group I). An insignificant increase in the body weight was observed after the treatment of methotrexate. Similarly, no significant alteration was observed in the body weights of the hydro- methanolic and aqueous dual extract treated groups, as well as in the silymarin treated group, after treatment for $30 \mathrm{~d}$.

\section{Organ weight}

MTX treatment caused a significant decrease in the net liver weight when compared to control, Group 1(fig. 2). A significant recovery was observed in organ weights of silymarin and extract treated groups (Group 3, 4 and 5) when compared with methotrexate administered group.

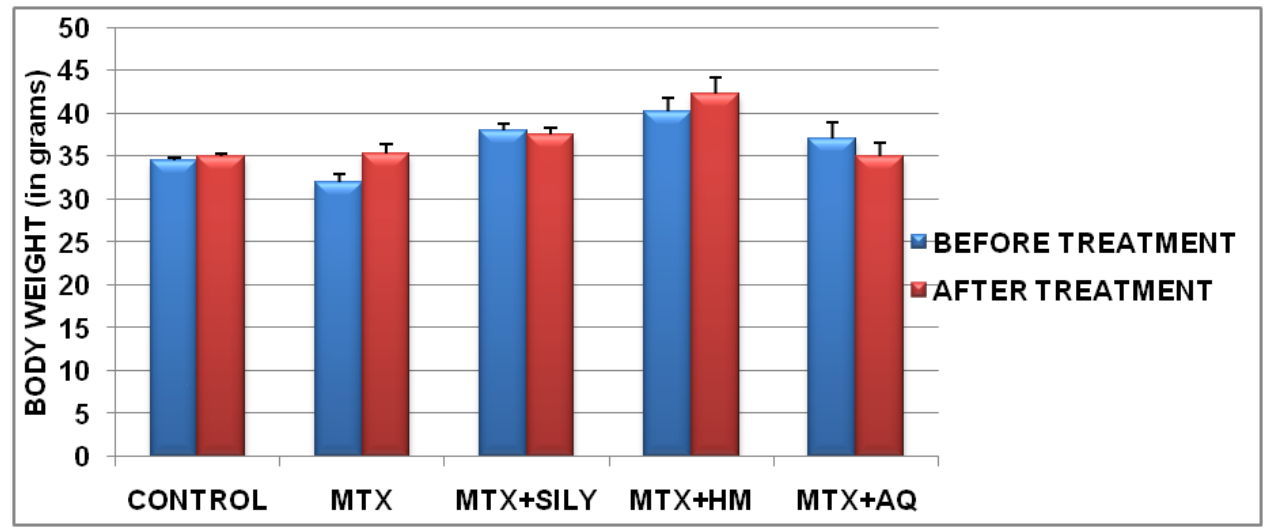

Fig. 1: Body weights of control, treated and ameliorated animals before and after treatment with hydromethanolic and aqueous extracts of dual formulation, Values are mean $\pm S E M, n=6, M T X=$ methotrexate, $H M=$ hydromethanolic extract, $A Q=$ Aqueous extract

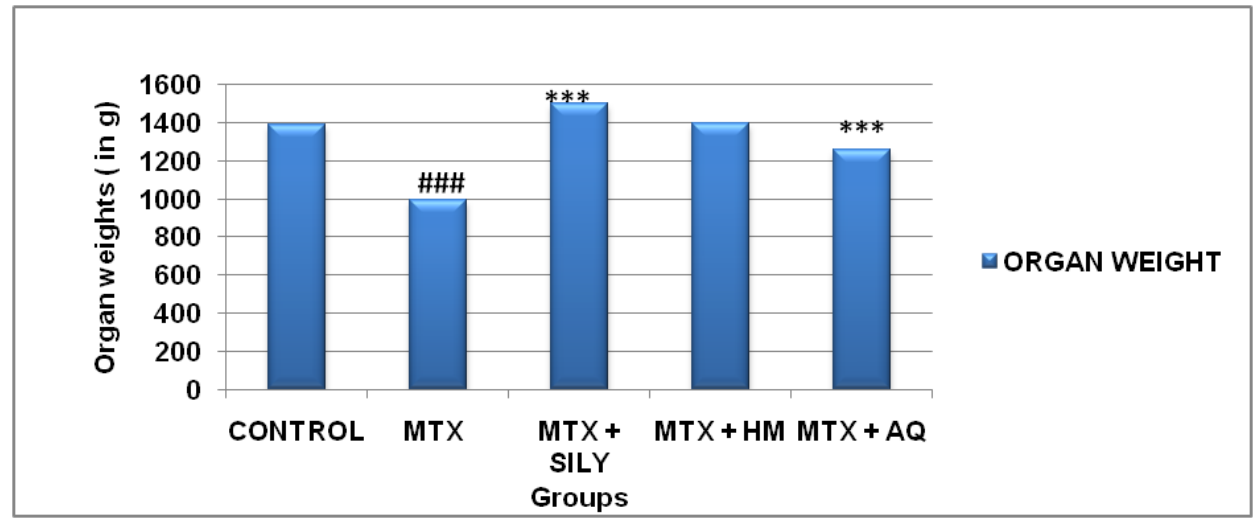

Fig. 2: Comparision between liver weight of control, methotrexate treated and dual extract treated animals, Values are expressed as MEAN \pm SEM, $n=6 /$ Group, \# = Compared with control, ${ }^{* * *} \mathrm{P}<0.001$, ${ }^{*}=$ Compared with Methotrexate (MTX), HM = hydromethanolic extract, $\mathrm{AQ}=$ Aqueous extract, $\mathrm{SILY}=$ silymarin

\section{ALT and AST activity}

ALT (SGPT) and AST (SGOT) activity was altered by Methotrexate administration. As is evident from table 3, ALT and AST levels were significantly increased $(\mathrm{p}<0.001)$ after drug treatment as compared to control (Group 1). Oral administration of the dual formulation (Murraya koenigii and Plumeria rubra) brought about a significant $(\mathrm{p}<0.05)$ restoration in ALT and AST activity in the extract treated groups (3, 4 and 5), lowering the elevated values caused by the drug. Both the aqueous as well as hydromethanolic extracts were able to significantly $(\mathrm{p}<0.001)$ mitigate the toxic alteration caused by the drug. However, Hydromethanolic dual extract was observed to be as effective as silymarin in recovering the elevated AST levels.

Table 3: ALT and AST activity in liver of control, methotrexate-treated, hydromethanolic and aqueous extract of dual formulation treated mice

\begin{tabular}{llll}
\hline S. No. & Groups & ALT & AST \\
\hline 1 & CONTROL & $81.99 \pm 3.00$ & $165.4 \pm 6.86$ \\
2 & MTX & $138.9 \pm 16.73^{\# \# \#}$ & $260.3 \pm 4.3^{\# \# \#}$ \\
3 & MTX+SILYMARIN & $99.80 \pm 1.65^{* * *}$ & $178.4 \pm 3.98^{* * *}$ \\
4 & MTX+HM & $110.0 \pm 3.26^{* *}$ & $187.6 \pm 1.78^{* * *}$ \\
5 & MTX+AQ & $122.6 \pm 4.9$ & $202.5 \pm 4.03^{* *}$ \\
\hline
\end{tabular}

Values are mean \pm SEM, $\mathrm{n}=6 /$ Group, $\#=$ compared with control, ${ }^{*}=$ compared with Methotrexate(MTX), ${ }^{* * *} \mathrm{p}<0.001,{ }^{* *} \mathrm{p}<0.05$, ALT and AST expressed as IU/l, $\mathrm{HM}=$ hydromethanolic extract, $\mathrm{AQ}=$ Aqueous extract 


\section{ALP and phosphorylase activity}

Methotrexate treatment for $30 \mathrm{~d}$ brought about a significant $(\mathrm{p}<0.001)$ elevation in ALP and Phosphorylase activity in the liver of MTX exposed group (Group 2) as compared to control group (Group 1). Silymarin, as well as the dual extracts, both hydro- methanolic and aqueous, brought about a significant $(\mathrm{p}<0.001)$ decline in ALPase as well as the Phosphorylase enzyme activity, suggesting a possible mitigative property of the extract, bringing the values to near normal activity. In addition, HM extract was seen to be more potent than aqueous extract in combating toxicity caused by the drug (table 4).

Table 4: Alkaline phosphatase and Phosphorylase levels in control, treated and dual formulation treated liver tissue

\begin{tabular}{llll}
\hline S. No. & Group & ALP & Phosphorylase \\
\hline 1 & CONTROL & $0.9583 \pm 0.11$ & $31.78 \pm 0.87$ \\
2 & MTX & $4.579 \pm 0.33^{\# \# \#}$ & $116.4 \pm 0.31^{\# \# \#}$ \\
3 & MTX+SILYMARIN & $1.407 \pm 0.05^{* * *}$ & $46.36 \pm 1.98^{* * *}$ \\
4 & MTX+HM & $0.8287 \pm 0.07^{* * *}$ & $41.64 \pm 5.16^{* * *}$ \\
5 & MTX+AQ & $1.265 \pm 0.07^{* * *}$ & $35.07 \pm 1.74^{* * *}$ \\
\hline
\end{tabular}

Values are mean \pm SEM, $n=6 /$ Group, ${ }^{* * *} \mathrm{p}<0.001, \#=$ compared with control, ${ }^{*}=$ compared with methotrexate (MTX), ALP expressed as $\mu \mathrm{g}$ of inorganic p-nitrophenol released/mg protein $/ 15^{\prime}$ and Phosphorylase expressed as $b=\mu \mathrm{g}$ of inorganic phosphate released $/ \mathrm{mg} \operatorname{protein} / 15^{\prime}, \mathrm{HM}=$ hydromethanolic extract, $\mathrm{AQ}=$ Aqueous extract

\section{Protein content in liver}

Protein concentration was observed to increase significantly $(\mathrm{p}<0.05)$ in the liver of drug administered group (Group 2) as compared to control. On the other hand, dual extract treatment (Murraya koenigii and Plumeria rubra; hydromethanolic and aqueous) was found to lower the protein levels and hence a significant recovery was observed in these groups (Group 4 and 5) $(\mathrm{p}<0.01)$. Silymarin treatment brought about an insignificant decline in the protein content after methotrexate administration. The aqueous dual extract was seen to be more potent in the recovery of the increased protein content (fig. 3).

\section{Cholesterol content in liver}

Methotrexate intoxication for $30 \mathrm{~d}$ induced a significant rise $(p<0.01)$ in the cholesterol content in the liver of the treated mice as compared to Control animals as shown by (fig. 3). The dual extract treatment brought about a significant reduction in the cholesterol content of the liver of treated groups, where the aqueous extract treatment proved more effective than the hydromethanolic extract in restoring the elevated cholesterol to near normal values $(\mathrm{p}<0.01)$.

\section{$\gamma$ glutamyl transpeptidase (GGT)}

Toxicity induced in the adult albino mice due to methotrexate treatment caused a significant increase $(p<0.01)$ in the serum GGT activity. Administration of dual extracts proved efficient in subsequently lowering GGT to near normal activity in both the extract treated groups (Group 4 and 5). The results indicated that the Hydromethanolic extract manifested more potent ameliorative action when compared with aqueous extract of the dual formulation (fig. 3).

\section{Lipid peroxidation}

As observed in table 5, a significant elevation $(\mathrm{p}<0.001)$ was observed in Lipid peroxidation (LPO) (Group 2) as a consequence of methotrexate administration. Oral administration of the aqueous extract proved as effective as silymarin in lowering the MDA content, which is the index of lipid peroxidation. This parameter was therefore significantly $(p<0.001)$ restored to values comparable to control.

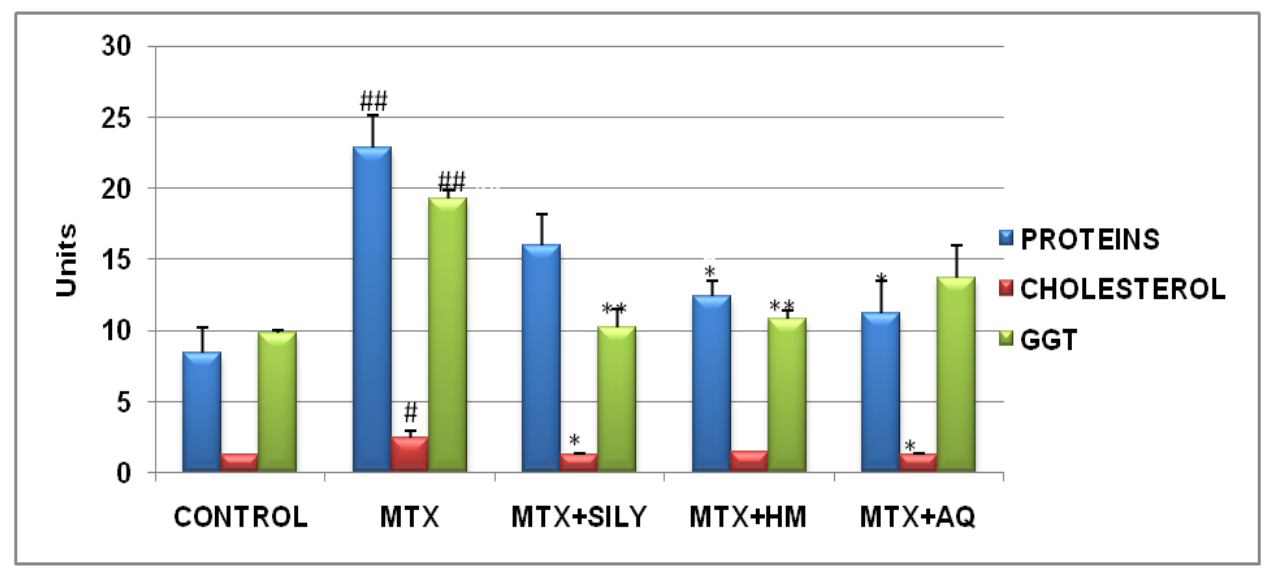

Fig. 3: Protein, Cholesterol and GGT concentration in control, MTX treated and DF treated liver tissue, Values are mean \pm SEM, $n=6 / G r o u p$, $\#=$ compared with control, ${ }^{*}=$ compared with methotrexate (MTX), ${ }^{* *}$ p $<0.05,{ }^{*} p<0.01$, protein and cholesterol expressed as mg/dL, GGT expressed as IU/l, HM = hydromethanolic extract, $A Q=$ aqueous extract, SILY=silymarin

\section{Superoxide dismutase and catalase activity}

A remarkably significant $(p<0.001)$ decline was observed in SOD and CAT activity in MTX treated groups of mice when compared to control. SOD activity in liver, however, manifested a significant $(\mathrm{p}<0.001)$ recovery in the silymarin and the extract treated groups (Group 3, 4 and 5) with resultant values comparable to control. The data indicated that the HM extract was more effective in alleviating the inhibition of SOD activity as compared to AQ (table 5).

A recovery was also recorded in the Catalase activity in liver tissue and the activity significantly increased in the dual extract treated groups as well as in silymarin treated group (Group 3, 4 and 5) with resultant values comparable to control. 
Table 5: Lipid peroxidation, superoxide dismutase and catalase levels in liver of control, treated and dual extract formulation treated groups

\begin{tabular}{lllll}
\hline S. No. & Groups & LPO & SOD & CAT \\
\hline 1 & CONTROL & $28.85 \pm 4.91$ & $0.63 \pm 0.45$ & $1.490 \pm 0.03$ \\
2 & MTX & $161.6 \pm 4.43^{\# \# \#}$ & $0.31 \pm 0.11$ & $0.2530 \pm 0.003^{\# \# \#}$ \\
3 & MTX+SILYMARIN & $30.38 \pm 1.53^{* * *}$ & $0.60 \pm 0.35^{* * *}$ & $0.7440 \pm 0.005^{* * *}$ \\
4 & MTX+HM & $6.467 \pm 1.80^{* * *}$ & $0.55 \pm 0.31^{* * *}$ & $0.8577 \pm 0.018^{* * *}$ \\
5 & MTX+AQ & $24.36 \pm 0.89^{* * *}$ & $0.65 \pm 0.33^{* * *}$ & $1.207 \pm 0.06^{* * *}$ \\
\hline
\end{tabular}

Values are mean \pm SEM, $\mathrm{n}=6 /$ Group, ${ }^{* * *} \mathrm{p}<0.001, \#=$ compared with control, ${ }^{*}=$ compared with methotrexate (MTX), LPO expressed as nM of $\mathrm{MDA} / \mathrm{mg}$ tissue weight/60 min, SOD expressed as units/mg protein, CAT expressed as $\mu$ moles $\mathrm{H}_{2} \mathrm{O}_{2}$ consumed/min/mg protein, $\mathrm{HM}=$ hydromethanolic extract, $\mathrm{AQ}=$ aqueous extract, $\mathrm{SILY}=$ silymarin

\section{DISCUSSION}

Methotrexate is a drug used widely for the treatment of different types of cancers and autoimmune diseases like rheumatoid arthritis [22]. Tripathi et al., [23] have reported that it has been used as a first line drug in many autoimmune diseases pemphigus, myasthenia gravis, uveitis, chronic active hepatitis. Therefore a large quantum of patients is at a potential risk of liver damage induced by such drugs. Hence, there is a need for producing a simple, easily available and effective hepatoprotective agent which could be administered along with the treatment of these ailments. Thus two plants (Murraya koenigii and Plumeria rubra) which are known to show some hepatoprotective activity were selected to be given in combination so that a potent hepatoprotective agent could be produced due to the supplementative and synergistic action of both the plants. The efficacy of this formulation was checked against methotrexateinduced hepatotoxicity.

Studies carried out earlier at our laboratory also indicated that Murraya koenigii manifested potent ameliorative action against Carbon tetrachloride induced gastrotoxicity [6] and also shows alleviation against methotrexate-induced liver toxicity [7]. Plumeria rubra also is known to treat Asthma, ease constipation, promote menstruation and reduce fever. The latex is used to soothe irritation [24]. The plant is a potent anticancer agent [25] and antihyperglycemic agent [26].

The phytochemical constituents of Plumeria rubra lacked the presence of saponins, steroids and triterpinoids. M. Koenigii, on the other hand, contained a high content of saponins and a mild presence of steroids and triterpenoids. P. rubra was found to have glycosides which were not detected in Murraya koenigii. Based on the phytochemical complementation of both the plants, $M$. koenigii and $P$. rubra were selected as a possible restorative agent to offset drug induced toxicity. Therefore, the present study was focussed to develop a dual herbal formulation taking advantage of proven hepatoprotective plant extracts, which could supplement each other in phytochemical components, and prove effective for drug-induced liver toxicity in male albino mice of Swiss strain.

The results of the present study revealed that the administration of drug methotrexate caused an insignificant increase in body weight. Highland et al., [7] reported that the administration of methotrexate caused an insignificant increase in body weight, possibly due to inhibition of biosynthetic and metabolic processes from the toxic impact of methotrexate. The decrease in liver weight on methotrexate administration possibly reflects inhibition of tissue synthesis within the tissue. The dual extract treatment significantly brought organ weight close to normal control, correlated with the data obtained indicating restoration of disturbed liver metabolic processes.

A significant increase in serum activities of enzymes alanine aminotransferase (ALT), and aspartate aminotransferase (AST) was observed in MTX treated group which are markers of liver inflammation and are the major critical liver enzymes involved in the metabolism of amino acids and electron transport chain [27, 28]. Treatment with the dual extracts modulated the effect of MTX, bringing about a recovery in the elevated enzyme activities comparable to the effect of silymarin. Elevation in these serum enzymes activities in MTX treated group reflects liver dysfunction which correlates with the cellular enzyme leakage due to alterations in plasma membrane permeability of hepatocytes.

Several researchers [29-32] reported increased levels of ALT by a single dose of methotrexate. Sener et al., [33] have explained that MTX treatment increased the intracellular hepatocyte polyglutamate concentration and decreased the folic acid content causing liver damage.

Silymarin is a known, recognised hepatoprotective agent reported to preserve the structural integrity of hepatocellular membrane and protect the liver from the harmful effects of this hepatotoxin. Vardi et al., [34] also observed the effect of a polyherbal formulation on MTX induced hepatotoxicity in rats, but full attenuation was not reported.

The dual extracts when administered in this investigation to MTX treated animals could bring about a recovery in the leached, elevated serum transaminases and other enzymes which could be attributed to the free radical scavenging action of the extracts, which in turn exerted a protective action on the integrity of the hepatocyte membrane, preventing peroxidation of membrane lipids and subsequent leakage of enzymes. This was possibly due to their potent phytochemical components, flavonoids in particular, which can alleviate such inflammation. Additionally, HM extract was found to be as effective as silymarin extract in reducing drug induced toxicity.

MTX treatment caused elevation in alkaline phosphatase and phosphorylase activity. Alkaline phosphatase is a hydrolase enzyme, which hydrolyses monophosphates at alkaline $\mathrm{pH}$ and serves as marker for hepatobiliary damage which gets eliminated in the bile. It is particularly present in the cells which line the biliary ducts of the liver and is elevated if bile excretion is inhibited by liver damage. Hepatotoxicity leads to elevation of the normal values due to the body's inability to excrete it through bile due to the congestion or obstruction of the biliary tract. Hepatic glycogen phosphorylase (GP) is the key regulatory enzyme in glycogenolysis as it catalyses the addition of phosphate group from an inorganic phosphate to an acceptor.

Our results corroborate with the observations made by [31] and [30]. Olayinka et al. [35] also observed similar results of increase in ALPase and phosphorylase activity following MTX treatment. However, following administration of the Dual extract, both hydromethanolic and aqueous extract a significant reversal could be recorded in these enzyme activities which substantiated the hypothesis of the hepatoprotective efficacy of the combined formulation. These values were ameliorated to near normal values.

In the course of treatment with methotrexate, protein and cholesterol contents were observed to be elevated. Protein concentrations are indicative of liver biosynthetic activity. Elevation in protein content in drug induced group was seen may be due to unscheduled synthesis of protein. MTX reduces cholesterol turnover, which causes its accumulation in liver leading to a condition known as steatosis. Therefore, increase in cholesterol content under the influence of drug causes steatosis, for which $\gamma$ glutamyl transpeptidase (GGT) is a known marker enzyme. Increase in cholesterol leads to an elevation in GGT activity. On the other hand, treatment with the dual extracts orally rendered a significant decline in protein and cholesterol content and GGT activity, in comparison to MTX treated groups bringing about a possible reversal and recovery. This recovery was found to be even more significant than that manifested by M. Koenigii alone as reported earlier by Highland 
et al., [7]. Plumeria rubra extracts alone were reported to effectively ameliorate $\mathrm{CCl}_{4}$ toxicity in liver, however in the present investigation, a highly significant recovery was observed, in comparison to administration of M. koenigii and P. rubra alone which indicates a synergistic action of the phytochemicals in the extracts.

Further, protective antioxidant enzymes in liver tissue like Superoxide dismutase (SOD) and catalase (CAT), which are involved in ROS scavenging, were observed to be reduced significantly after treatment with methotrexate compared to healthy, untreated group. On the other hand, the SOD and CAT activities were significantly ameliorated in all groups treated with dual extracts, causing an enhancement in these free radical scavenging enzymes, compared to the MTX dosed group. The data published by Jasprica et al.,[36] and Hemeida and Mohafez [37], who studied biochemically, liver activities under the influence of MTX explained that enzyme activity of superoxide dismutase (SOD) and catalase (CAT) were notably reduced, while lipid peroxidation, expressed as malondialdhyde (MDA) level was significantly increased, and this validates our results. Lipid peroxidation was observed to be significantly pronounced in animals treated with methotrexate in our study. Sener et al. [33] reported that ROS-mediated lipid peroxidation plays a major role in the cell membrane destruction which hampers the normal functions of the cell which may be the probable cause of MTX mediated tissue damage. LPO is measured in the form of MDA content. This enhanced LPO was significantly reversed in dual extract administered groups, an observation which could be correlated with the augmented activities of SOD and CAT triggered by the dual formulation in this study. The tested formulation could therefore efficiently resolve the free radical toxicity induced by methotrexate, indicating its potent ROS scavenging property.

\section{CONCLUSION}

Drug induced toxicity is major threat to the liver. Earlier studies carried out at our laboratory revealed that Murraya koenigii and Plumeria rubra were both effective individually as hepatoprotective agents, bringing about recovery in the methotrexate induced liver injury. However, the phytochemical analysis indicated that the individual plant extracts lacked certain vital phytoconstituents, which were compensated when two plant extracts were combined.

Thus it is evident from the results of the present study that a simple formulation made from these two effective herbal plants could result in a potent hepatoprotective agent avoiding the complexities of a polyherbal formulation with uncertain interactions and side effects. Moreover, unlike silymarin, the constituents of the formulation are easily available locally. The present study also indicates that there is a scope of intervention of drug-induced hepatotoxicity by simple formulations combining two extracts for amelioration of liver injury.

\section{AUTHOR CONTRIBUTION}

1. Carried out research and experimentation

2. Helped in research experimentation

3. Supervised the research program and manuscript development

4. Designed the problem and analysed results.

\section{REFERENCES}

1. Wang Z, Masternak MM, Al-Regaiey KA, Bartke A. Adipocytokines and the regulation of lipid metabolism in growth hormone transgenic and calorie-restricted mice. Endocrinology 2007;148:2845-53.

2. Zimmerman HJ, Maddrey WC. Acetaminophen (paracetamol) hepatotoxicity with regular intake of alcohol: analysis of instances of therapeutic misadventure. Hepatol 1995;22:767-73.

3. Russmann S, Kullak-Ublick GA, Grattagliano I. Current concepts of mechanisms in drug-induced hepatotoxicity. Curr Med Chem 2009;16:3041-53

4. Oreagba IA, Oshikoya KA, Amachree M. Herbal medicine use among urban residents in Lagos, Nigeria. BMC Complementary Altern Med 2011;25:111-7.
5. Efferth T, Koch E. Complex interactions between phytochemicals. The multi-target therapeutic concept of phytotherapy. Curr Drug Targets 2011;12:122-32.

6. Highland H, Engineer A, Jethva H, Desai K. Role of hydroalcoholic and aqueous leaf extracts of Murraya koenigii in gastroprotection. Int J Pharmacol Res 2015;5:301-9.

7. Highland HN, Kanwar R, Engineer A, Desai KR. Effective alleviation of methotrexate induced hepatotoxicity by Murraya koenigii leaf extracts. Eur J Pharm Med Res 2016;3:439-47.

8. Rastogi RP, Mehrotra BN, Pastogi RP. Compendium of Indian medicinal plants. Vol. 1. Central Drug Research Institute; Publications and Information Directorate; 1995. p. 394.

9. Adebajo AC, Olayiwola G, Eugen Verspohl J, Iwalewa EO, Omisore NO, Bergenthal D, et al. Evaluation of the ethnomedical claims of Murraya koenigii. Pharm Biol 2005;42:610-20.

10. Bandyopadhyay D, Ghosh D, Chattopadhyay A, Mitra E. Curry leaves as alternative medicine in heavy metal induced occupational health hazards. Int J Pharm Pharm Sci 2016;8:820.

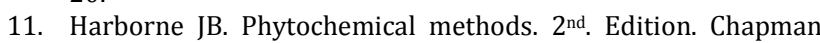
and Hall publications, London, NewYork; 1984. p. 288

12. Kokate CK. A Textbook for Practical Pharmacognosy. $5^{\text {th }}$ edn; 2005.

13. Blois MS. Antioxidant determinations by the use of a stable free radical. Nature 1958;181:1199-200.

14. Yamasaki K, Hashimoto A, Kokusenya Y, Miyamoto T, Sato T. Electrochemical method for estimating the antioxidative effects of methanol extracts of crude drugs. Chem Pharm Bull 1994;42:1663-65.

15. Cori CF, Cori GT, Green AA. Crystalline muscle phosphorylase III. Kinetics J Biol Chem 1943;151:39-55.

16. Bessey OA, Lowky OH, Brock MJ. A method for the rapid determination of alkaline phosphatase with five cubic millimeters of serum. J Biol Chem 1946;164:321-9.

17. Ohkawa H, Ohishi N, Yagi K. Assay for lipid peroxides in animal tissues by thiobarbituric acid reaction. Anal Biochem 1979;95:351-8.

18. Kakkar P, Das B, Viswanathan PN. A modified spectophotometric assay of superoxide dismutase. Indian J Biochem Biophys 1984;21:130-2.

19. Sinha AK. Colorimetric assay of catalase. Anal Biochem 1972;47:389-94.

20. Lowry $\mathrm{OH}$, Rosebrough NJ, Farr AL, Randall RJ. Protein measurement with the folin phenol reagent. J Biol Chem 1951;193:265-75.

21. Zlatkis A, Zak B, Boyle AJ. A new method for the direct determination of serum cholesterol. J Lab Clin Med 1953;41:486-92.

22. Khan ZA, Tripathi R, Mishra B. Methotrexate: a detailed review on drug delivery and clinical aspects. Expert Opinion Drug Delivery 2012;9:151-69.

23. Tripathi KD. Essentials of pharmacology. Second edition. Jaypee publishers; 2015. p. 314-6.

24. Wiart C. Medicinal plants of Southeast Asia. $2^{\text {nd }}$ Edn. Malaysia: Prentice Hall; 2002.

25. Rekha JB, Jayakar B. Anti cancer activity of ethanolic extract of leaves of Plumeria rubra (Linn). Curr Pharm Res 2011;1:175-9.

26. Merina AJ, Sivanesan D, Begum VH, Sulochana N. Antioxidant and hypolipidemic effect of Plumeria rubra L. in alloxan induced hyperglycemic rats. J Chem 2010;7:1-5.

27. Maiti R, Jana D, Das UK, Ghosh D. Antidiabetic effect of aqueous extract of seed of tamarindus indica in streptozotocin-induced diabetic rats. J Ethnopharmacol 2004;92:85-91.

28. Wali AF, Avula B, Ali Z, Khan IA, Mushtaq A, Rehman MU, et al. Antioxidant, hepatoprotective potential and chemical profiling of propolis ethanolic extract from Kashmir Himalaya region using UHPLC-DAD-QToF-MS. BioMed Res Int 2015;11:2015.

29. Fu Y, Zheng S, Lin J, Ryerse J, Chen A. Curcumin protects the rat liver from $\mathrm{CCl} 4$-caused injury and fibrogenesis by attenuating oxidative stress and suppressing inflammation. Mol Pharmacol 2008;73:399-409. 
30. Uraz S, Tahan V, Aygun C, Eren F, Unluguzel G, Yuksel M, et al. Role of ursodeoxycholic acid in prevention of methotrexateinduced liver toxicity. Dig Dis Sci 2008;53:1071-7.

31. Vaghasiya J, Bhalodia Y, Rathod S. Drug induced hepatotoxicity: effect of polyherbal formulation. Pharmacogn Mag 2009;5:232.

32. De S, Sen T, Chatterjee M. Reduction of oxidative stress by an ethanolic extract of leaves of Piper betle (Paan) Linn. decreased methotrexate-induced toxicity. Mol Cell Biochem 2015;409:191-7.

33. Şener G, Ekşioğlu-Demiralp E, Cetiner M, Ercan F, Şirvancı S, Gedik N, et al. L-Carnitine ameliorates methotrexate-induced oxidative organ injury and inhibits leukocyte death. Cell Biol Toxicol 2006;22:47-60.

34. Vardi N, Parlakpinar H, Cetin A, Erdogan A, Cetin Ozturk I. Protective effect of $\beta$-carotene on methotrexate-induced oxidative liver damage. Toxicol Pathol 2010;38:592-7.
35. Olayinka ET, Ore A, Adeyemo OA, Ola OS. Ameliorative effect of gallic acid on methotrexate-induced hepatotoxicity and nephrotoxicity in rat. J Xenobiotics 2016;6:14-8.

36. Jasprica I, Mornar A, Debeljak Z, Smolcic-Bubalo A, Medic-Saric $\mathrm{M}$, Mayer L, et al. In vivo study of propolis supplementation effects on antioxidative status and red blood cells. J Ethnopharmacol 2007;110:548-54.

37. Hemeida RA, Mohafez OM. Curcumin attenuates methotraxateinduced hepatic oxidative damage in rats. J Egypt Natl Cancer Inst 2008;20:141-8.

\section{How to cite this article}

- Engineer AS, Pal S, Desai KR, Highland HN. Synergistic antioxidant action of Murraya koenigii and Plumeria rubra extracts enhance hepatoprotective efficacy against methotrexate induced liver injury. Int J Pharm Pharm Sci 2017;9(10):152-159. 